\title{
Revista Filosofía UIS
}

Vol. $20 n^{\circ} 1$ (2021) I enero - junio

revistafilosofia@uis.edu.co

Universidad Industrial de Santander

Colombia

\section{Enfrentamiento epistemológico entre Hegel y Kant}

\section{Epistemological Confrontation between Hegel and Kant}

\author{
Alan Tonatiuh López Niño* \\ zagato00@gmail.com \\ (iD) https://orcid.org/0000-0002-2208-4175 \\ Instituto de Investigaciones Sociales y Humanas, México \\ Artículo de reflexión derivado de investigación \\ Recepción: 9 de junio de 2020 \\ Aprobación: 9 de julio de 2020 \\ https://doi.org/10.18273/revfil.v20n1-2021008
}

\begin{abstract}
(c) (i)
Resumen: la presente investigación ciñe su interés en llevar a cabo un análisis del pensamiento hegelianokantiano utilizado para construir el concepto de sustancia como sujeto y su relación con la formación del conocimiento real dentro de la conciencia. Por tanto, comenzamos teorizando desde el postulado de la filosofía kantiana dónde se desarrolla el significado de nóumeno y sus consecuencias en el terreno práctico visto desde su obra Crítica de la razón pura. Partimos de este escenario porque, consideramos que gran parte de la explicación epistemológica de la Fenomenología del espíritu enunciada por Hegel, se edifica a raíz de su confrontación con el criticismo de Kant. En conclusión, la especificidad de los problemas y controversias que ambas filosofías comparten, hacen necesario reflexionar y esclarecer sus apreciaciones acerca de la concepción del conocimiento, aunado a que, para educadores, psicólogos y sociólogos es imprescindible desentrañar las formas en que se concibe el conocimiento y, por tanto, la constitución de lo real desde ambas posturas epistemológicas.
\end{abstract}

Palabras clave: teoría del conocimiento, epistemología, constitución de conciencia, relación sujeto-objeto, idealismo objetivo, realidad.

Abstract: this research focuses on his interest in carrying out an analysis of Hegelian-Kantian thought used to construct the concept of substance as subject and its relation to the formation of real knowledge within consciousness. Therefore, we begin by theorizing from the postulate of Kantian philosophy where the meaning of noumene and its consequences are developed in the practical field seen from his Critique of Pure Reason. We start from this scenario because we consider that a large part of Hegel's epistemological explanation of the Phenomenology of Spirit is built as a result of his confrontation with Kant's criticism. In conclusion, the specificity of the problems and controversies that both philosophies share, make it necessary to reflect and clarify their opinions about the conception of knowledge, in addition to the fact that, for educators, psychologists and sociologists it is essential to unravel the ways in which the knowledge and, therefore, the constitution of the real from both epistemological positions.

Keywords: theory of knowledge, epistemology, constitution of consciousness, subject-object relationship, objective idealism, reality.

* Mexicano. Magíster en pedagogía de las Ciencias Sociales. Estudiante de doctorado en el Instituto de Investigaciones Sociales y Humanas, México.

Forma de citar (APA-7): López-Niño, A. T. (2021). Enfrentamiento epistemológico entre Hegel y Kant. Revista Filosofía UIS, 20(1). 179203. https://doi.org/10.18273/revfil.v20n1-2021008 


\title{
1. Introducción
}

\author{
Los hábitos de nuestros sentidos nos han envuelto en una tela de sensaciones \\ engañosas que son, a su vez, la base de todos nuestros juicios y de nuestro \\ «Conocimiento». No hay salida ni escape posibles; no hay acceso alguno al mundo \\ real. Estamos dentro de una tela de araña, y sólo podemos captar con ella aquello \\ que se deje aprehender. \\ (Nietzsche, 1993, p. 83)
}

Si nos remitimos a los textos filosóficos clásicos y hacemos un repaso a la historia de la filosofía, seguramente deduciremos que Hegel tuvo una profunda influencia kantiana, sobre todo en los años de juventud de su pensamiento; sin embargo, dicha influencia debe ser estudiada a la luz de los temas puntuales de gran relevancia en el ámbito intelectual de la época, siendo uno de estos la epistemología kantiana. En efecto, Kant y, particularmente, su obra Crítica de la razón pura significó un punto de quiebre en el debate filosófico de la Alemania de finales del siglo XVIII (Manzano Vargas, 2013). No obstante, ¿cuáles fueron los temas puntuales sobre la teoría del conocimiento que causaron más inquietud en el joven Hegel y, por tanto, provocaron que este engendrara diversos puntos de vista los cuales confrontaría con Kant?

El presente artículo expone algunos de los aspectos más importantes que componen la controversia entre Kant y Hegel acerca de un tema específico que, a decir verdad, define de forma trascendente y sistemática la epistemología de la época: construir el concepto de sustancia como sujeto y su relación con la formación del conocimiento real dentro de la conciencia.

Por tanto, la primera parte de este escrito, titulada "Sobre la posibilidad de la metafísica", versa acerca del estatus de la metafísica entre las ciencias y se ciñe en el debate entre el empirismo y la nueva filosofía que Kant pretendía inaugurar y que es una de las razones por las que Kant se vio forzado a admitir la existencia de la cosa en sí (noúmeno) en oposición al fenómeno.

En la segunda parte, titulada "Noumenicidad kantiana y el en sí hegeliano como momento de la conciencia" se explica cómo es que Kant desarrolla el concepto de nóumeno como una noción que no tiene la finalidad de ampliar nuestro conocimiento, sino, más bien, de delimitarlo. En este sentido, 
la respuesta que ofrece Hegel a la problemática sobre la posibilidad de existencia de una característica propia de nuestro mismo entendimiento que obstaculiza el conocimiento de la realidad consiste en colocar este límite dentro de la conciencia, de modo que deja abierta la posibilidad de superarlo y acceder a la cosa en sí.

La tercera y última sección de este artículo se titula "Crítica hegeliana del criticismo kantiano" y aborda tres de los presupuestos kantianos que, desde la perspectiva de Hegel, representan puntos de vista unilaterales que imposibilitan la comprensión efectiva de la realidad. Estos tres supuestos son: 1) la representación del conocimiento como un instrumento o un médium, 2) la diferenciación entre nosotros mismos y ese conocimiento y, finalmente, 3) la escisión entre el absoluto y el conocimiento. Las alternativas que ofrece Hegel en oposición a estos tres presupuestos kantianos, son el punto de partida de una filosofía que pretende comprender la completitud de las figuras de la conciencia con miras a explicar cómo es que la conciencia recorre el camino desde la inmediatez hasta la adecuación entre pensamiento y realidad.

\section{Sobre la posibilidad de la metafísica}

En gran medida, la originalidad de Kant reside en haberle otorgado una forma estrictamente filosófica - y ya no solamente escéptica— al problema de la naturaleza limitada de la razón humana. Este giro, llevado a cabo por parte de Kant en la teoría del conocimiento, es, de hecho, uno de los motivos de interés de Hegel debido a las consecuencias negativas para la metafísica. A diferencia del escepticismo, para Kant la dificultad que conlleva el uso metafísico de la razón no implica la necesidad de renunciar a la posibilidad de conocimiento y, por tanto,

[...] el cuestionamiento sobre la capacidad de la razón es más bien una premisa y parte importante del método kantiano con miras a que la razón se examine a sí misma y pueda sentar de una vez por todas los alcances de su actividad. (Manzano Vargas, 2013, p. 18)

Sin embargo, aunque Hegel comparte algunos de los rasgos definitorios de la teoría kantiana, difiere sustancialmente en otros y desarrolla una postura por completo distinta. Kant comienza la Crítica de la razón pura con una 
afirmación que deja en claro la contradicción interna que existe entre aquello a lo que tiende naturalmente la razón y su capacidad.

La razón humana tiene el destino singular, en uno de sus campos de conocimiento, de hallarse acosada por cuestiones que no puede rechazar por ser planteadas por la misma naturaleza de la razón, pero a las que tampoco puede responder por sobrepasar sus facultades. (Kant, 2006, p. 7)

Esta relación problemática de la razón consigo misma recorre la modernidad como una relación de tensión entre la metafísica y los desarrollos de la nueva ciencia y significa también — como se ha mencionado con anterioridad- una confrontación entre el escepticismo y la nueva postura filosófica que Kant pretende inaugurar. Dicha confrontación entre el escepticismo y la postura de Kant podría resumirse en los puntos que se abordan a continuación.

Para el escepticismo, si la razón se encuentra, de suyo, incapacitada para resolver preguntas que ella misma se plantea, entonces debería renunciar a aquellas y dedicarse a cuestiones que estén de hecho a su alcance. Según Kant, David Hume es el filósofo que más había penetrado en el problema de la imposibilidad de la metafísica como ciencia. Siguiendo a Hume, Kant (2006) dice que "todo lo que llamamos metafísica vendría a ser la mera ilusión de pretendidos conocimientos racionales de algo que, de hecho, sólo procede de la experiencia y que adquiere la apariencia de necesidad gracias a la costumbre" (p. 54). Para Kant, el hecho que Hume negara el carácter científico de la metafísica, al mismo tiempo también aniquilaba la posibilidad de existencia de toda filosofía como un saber genuino, por lo que, la postura del filósofo alemán consiste en contribuir para que la metafísica dejara de ser un mero andar a tientas con base en simples conceptos para convertirse en la ciencia fundamental, aquella que sirva como punto de partida para el conjunto de las ciencias.

Sin embargo, la maniobra de Kant no consiste en volcarse por completo del lado del conocimiento especulativo para dejar a un lado el empírico, sino que, de hecho, afirma que "ningún conocimiento precede a la experiencia y todo conocimiento comienza con ella" (Kant, 2006, p. 42), de modo que, por un lado, concede al empirismo — que tanto ataca — la limitación del conocimiento 
solo a los fenómenos $y$, por el otro, concede al racionalismo $-\mathrm{y}$ con esto al pensamiento metafísico tradicional - el principio de atribuir a ese conocimiento empírico una validez necesaria y universal que únicamente procede del principio de autosubsistencia del pensar. Pese a esta bilateralidad, al afirmar que todo conocimiento comienza con la experiencia, Kant subordina el principio de la autosuficiencia del pensar al de la limitación del conocimiento a los fenómenos, en cuanto que niega que los conceptos y los principios del entendimiento tengan otra verdad que la que deriva de su uso empírico. Dicha limitación del conocimiento a los fenómenos tiene, no obstante, un origen diametralmente opuesto al del empirismo de Hume $y$, en general, a todo dogmatismo ${ }^{1}$ en el sentido kantiano del término.

Mientras el empirismo sostiene que ningún concepto o ley de la razón puede reclamar universalidad y necesidad, sino que únicamente debe su existencia a la costumbre o el hábito, de modo que los fenómenos, tal como se nos presentan, son la única fuente de conocimiento, Kant (2006) considera al objeto - el fenómeno- desde dos perspectivas: la primera, considerando el objeto en sí mismo como autosubsistente e independientemente del modo de intuirlo; y la segunda, estudiando al objeto, teniendo en cuenta la forma de intuirlo, la cual no ha de buscarse en el objeto mismo, sino en el sujeto al cual se le presenta (pp. 77-78). De este modo, aunque, en primera instancia, el objeto se presente ante nuestro entendimiento como una existencia ajena y exterior a nosotros, en realidad, aquel solo posee existencia en cuanto que es percibido por un sujeto. Aunque todo objeto en particular parezca poseer una existencia propia e independiente al sujeto y se presente como existente en un tiempo y espacio determinados por él mismo, Kant afirma que estos - espacio y tiemposon formas puras de toda intuición sensible, es decir, no más que meras condiciones de posibilidad de los objetos, propias al entendimiento y no al objeto, de las que pueden surgir a priori diferentes conocimientos sintéticos. Covarrubias Villa (2017) amplía la explicación cuando menciona:

Puede no existir la consciencia de la existencia de una racionalidad determinada en el sujeto y mucho menos del abanico de conexiones y pensamientos que están entrelazados en esa racionalidad y que muchos de ellos ni siquiera provienen del modo teórico de apropiación de lo real, pero están allí

\footnotetext{
${ }^{1}$ El dogmatismo es, para Kant, el procedimiento de la razón pura sin previa crítica de su propia capacidad.
} 
cumpliendo una función teórica plenamente integrados a los referentes teóricos que definen la racionalidad con la que opera la conciencia. (p. 17)

Según este argumento, es posible observar que, aunque Kant sostiene el carácter fundamental de los fenómenos como fuente primaria de conocimiento, por otro lado, abre la posibilidad de un tipo de conocimiento independiente a la experiencia sensible, todo esto en la medida en que niega la realidad - en el sentido fenoménico-espacial del término- del tiempo y espacio, y los coloca más bien como forma pura de toda intuición interna y externa, es decir, como fuentes de conocimiento y propiedades del sujeto cognoscente; de modo que “permanece para nosotros absolutamente desconocido qué sean los objetos en sí, independientemente de toda esa receptividad de nuestra sensibilidad. Solo conocemos nuestro modo de percibirlos" (Kant, 2006, p. 82). Esto significa que, si hiciéramos el ejercicio mental de suprimir el carácter subjetivo de los sentidos en general, tanto el conjunto de fenómenos que se nos dan a los sentidos, como el espacio y el tiempo mismos, dejarían de existir. En suma, "Kant no niega la existencia de los objetos en sí, pero aclara que es imposible conocerla dado que su apropiación fenoménica es inevitable. Pero la existencia misma de los objetos puede ser cuestionada" (Covarrubias Villa, 2017, p. 67).

Hasta aquí, se puede observar que el giro, llevado a cabo por Kant en la teoría del conocimiento, radica en invertir la manera en que se considera la relación entre el sujeto y los objetos que se le presentan —al afirmar que espacio y tiempo no son entes subsistentes por sí mismos, sino formas puras a priori de nuestro entendimiento o, bien, condición de posibilidad de los objetos-. Sin embargo, la disputa con los empiristas se decide en términos de saber si existe algún tipo de conocimiento independiente de la experiencia e, incluso, de las impresiones de los sentidos o, si, de hecho, la renuncia a la metafísica y la aceptación de que solo es conocimiento aquel que procede de las impresiones de los sentidos, son la mejor salida.

Kant entiende por conocimiento a priori a aquel que es completamente independiente de toda experiencia y no solamente independiente de esta o aquella experiencia. Tanto juicios, como conceptos — como el de sustancia: concepto clave en la historia de la filosofía - pueden existir a priori, esto significa que, si se despoja a un concepto de todas sus características empíricas 
específicas, aquel permanece. De hecho, un punto clave en la interpretación kantiana de la razón es considerar a la tarea de analizar los conceptos que ya poseemos y descomponerlos de tal modo que lleguemos a su origen —es decir, hasta la evidencia que este o aquel concepto tiene su origen a priori-, como una de las más importantes y, quizás, la más importante de ellas, todo esto en virtud de la posibilidad de una nueva filosofía, aquella "cuyo plan tiene que ser enteramente esbozado por la crítica de la razón pura de modo arquitectónico, es decir, a partir de principios, garantizando plenamente la completitud y la certeza de todas las partes que componen este edificio" (Kant, 2006, p. 59). En este sentido, la filosofía trascendental a la que Kant apunta como resultado de la crítica de la facultad de conocer, implicaría un tipo de conocimiento que se ocupa ya no de los objetos, sino más bien de nuestro modo de conocerlos, en tanto que este ha de ser posible a priori.

Sin embargo, el intento de armonizar los dos principios - el empirista y el racionalista- en su teoría del conocimiento fuerza a Kant a no reducir la cosa a su ser sensible y a separar este de su ser en sí, separación que, según Hegel, tiene como resultado un vacío de conocimiento y no como pretende Kant, un conocimiento de la forma del mismo. Este problema se convertirá en uno de los puntos clave de la crítica hegeliana al criticismo kantiano.

Ha llegado por fin la hora de sustituir la pregunta kantiana «żcómo son posibles los juicios sintéticos a priori?» por una pregunta distinta «por qué es necesaria la creencia en tales juicios?» - es decir, la hora de comprender que, para la finalidad de conservar seres de nuestra especie, hay que creer que tales juicios son verdaderos. (Nietzsche, 2007, p. 33)

\section{Noumenicidad kantiana y el en sí hegeliano como momento de la conciencia}

El cambio de viraje realizado por parte de Kant en la teoría del conocimiento y el giro que esto representa para la filosofía en su totalidad, tiene, para Hegel, una significación mucho más radical que la estrictamente epistemológica, ya que no afecta únicamente a la validez del conocimiento científico, sino al problema de la verdad del pensar mismo y algo mucho más importante, a la imposibilidad de transgredir el estado de cosas dadas y, por 
tanto, a la renuncia de todo intento de transformación de la realidad en el plano político.

Como se expone más adelante, todo el núcleo de conceptos más importantes en la filosofía hegeliana — libertad, sujeto, espíritu— están derivados del concepto hegeliano de razón, desarrollado a partir de la crítica y la superación de algunos de los supuestos de la filosofía crítica kantiana. De hecho, la subordinación de la idea al concepto de libertad es consecuencia del concepto hegeliano de razón. Como bien indica Marcuse (1979):

La razón presupone la libertad, el poder de actuar de acuerdo con el conocimiento de la verdad, el poder de dar forma a la realidad conforme a sus potencialidades. A su vez, la libertad, presupone la razón porque es sólo el conocimiento comprensivo lo que capacita al sujeto para obtener y ejercer ese poder. (p. 15)

Como podemos observar, razón y libertad son dos conceptos clave que se encuentran relacionados no de manera externa o accidental, sino que uno presupone al otro, sin embargo, debe mencionarse que, de hecho, esta relación conceptual interna entre ellos, se encuentra mediada por la previa superación de la separación kantiana del ser en sí de la cosa y su ser sensible. Por tanto, se puede suponer que en la explicación kantiana la relación de correspondencia en "un discurso teórico puede, según su nivel, versar tanto sobre objetos abstractos y formales como sobre objetos concretos y reales" (Althusser, 2000, p. 46)

Retrocedamos un poco hacia uno de los textos hegelianos más controvertidos debido a su fuerza y el tipo de lenguaje empleado en él, para entender por qué la separación kantiana del ser sensible de la cosa y su ser en sí significan para Hegel un problema epistemológico fundamental, así como una renuncia a la posibilidad de transformación del orden social. En el capítulo titulado "Primer programa de un sistema del idealismo alemán", Hegel (1978) señala que:

[...] sólo lo que es objeto de la libertad se llama idea. iPor lo tanto tenemos que ir más allá del Estado! Porque todo estado tiene que tratar a hombres libres como engranajes mecánicos, y puesto que no debe hacerlo debe dejar de existir". (p. 219) 
Ahora bien, ¿cómo es que un filósofo que supuestamente es defensor a muerte y glorificador del Estado prusiano, señalado como pieza clave en la formación del nacionalismo, autoritarismo y militarismo alemanes, señalaría que todo Estado que trate a hombres libres como simples piezas de un engranaje mecánico debería desaparecer? Y, ¿qué significación tiene el afirmar que solo lo que es objeto de la libertad se llama idea?

Como es posible saber, gracias a sus obras y a algunos documentos personales, para Hegel, el giro decisivo que dio la historia con la Revolución francesa consiste en que el hombre dejó de estar a merced de los hechos que lo rodeaban y se atrevió a someter la realidad dada a las normas de la razón (D'Hondt, 2002), es decir, a dar forma a la realidad conforme con las potencialidades mismas del pensar como rasgo definitorio de lo humano. Hegel nunca fue defensor del nacionalismo, sino que, de hecho, a pesar de su fuerte crítica hacia el terror producido por la Revolución francesa, le dio la bienvenida y la llamó aurora de la nueva era e, incluso, relacionó los principios básicos de su filosofía con los ideales que aquella representaba.

Así, lo más importante a destacar dentro de este Primer programa es que, pese a que la mayoría de sus ideas principales están fundamentadas en circunstancias de la época en que fue escrito —el fervor momentáneo por la Revolución francesa, impulsadas, al mismo tiempo por el repudio a la relación estrecha entre Estado y religión que dominaba en aquel momento y que irritaba profundamente a Hegel e influenciadas por el movimiento romántico de la época y por sus mismos compañeros y amigos, permitía justificar su pensamiento, puesto que solo lo que es objeto de la libertad puede ser llamado idea.

Aquella época que, a decir verdad, refleja consistentemente las ideas que, más adelante, serán defendidas por Hegel desde diferentes perspectivas, pero siempre apuntando hacia un mismo objetivo, esto es, la crítica a las circunstancias políticas en las que vivía el pueblo alemán.

En este caso en particular, se considera que esta afirmación — hecha muy tempranamente en el desarrollo filosófico de Hegel—, según la cual todo Estado que no trate a cada hombre como individuo libre debe desaparecer, está directamente conectada con uno de los puntos clave en la Fenomenología del 
espíritu, esto es, la crítica de la teoría kantiana de la separación entre el ser sensible de la cosa y su ser en sí: fenómeno y nóumeno (Fink, 2014, p. 134). Lo que se afirma con esto es que la contraposición entre Kant y Hegel - y de hecho toda contraposición desde el punto de vista filosófico-, aparentemente de carácter técnico-filosófico, arraiga muy profundas diferencias histórico-filosóficas de relevancia política.

Como se expuso anteriormente, al afirmar que todo conocimiento comienza con la experiencia, Kant subordina el principio de la autosuficiencia del pensar al de la limitación del conocimiento a los fenómenos, en cuanto que niega que los conceptos y los principios del entendimiento tengan otra verdad que la que deriva de su uso empírico. En este sentido, aun afirmando la existencia de un tipo de conocimiento dado a priori, este remite, en primera y última instancia, a la parte correspondiente a su uso empírico, por lo que queda cancelada la posibilidad de acceso al conocimiento de las cosas en sí mismas (Labrador Montero, 2018). La cosa en sí permanece como un más allá vacío, la " $\mathrm{x}$ " desconocida, que subyace al fenómeno y que, para nosotros, es incognoscible. Ya se ha comentado que, para Kant (2006), "todo cuanto el entendimiento extrae de sí mismo no lo tiene para otro fin, aunque no lo haya tomado de la experiencia, que el de un uso exclusivamente empírico" (p. 260), de modo que el hecho que una de las conclusiones más importantes en la filosofía de Kant —la de la existencia del nóumeno—signifique, a su vez, una vuelta a lo no empírico, provoca extrañeza — si no, desconfianza - en primera instancia.

El argumento kantiano consiste en defender la idea que, para que podamos suministrar un objeto al concepto, debe existir necesariamente una intuición. Es decir, aunque sea posible a priori una intuición pura con anterioridad al objeto, esa misma intuición solo puede recibir su objeto, es decir, su validez objetiva, a través de la intuición empírica de la que aquella solamente constituye una forma o, dicho de otro modo, un soporte sin el cual no podría ser posible dicha intuición empírica. Esto significaría que, tanto las categorías como las formas puras a priori de la intuición pasarían a ser no más que meras formas del pensamiento — como su nombre lo indica - encargadas de unificar a priori la variedad de objetos dada a la intuición. La consecuencia de este modo de operar culmina en que, inevitablemente, si los sentidos solo nos presentan algo tal como 
se manifiesta, tal como es dado, ese algo tiene que ser también una cosa en sí misma y un objeto de una intuición no sensible, esto es, un objeto de una intuición propia del entendimiento, una intuición intelectual, cuya existencia Kant niega rotundamente.

De esta forma es que surge en la teoría kantiana el concepto de nóumeno, al oponer a ciertos objetos en cuanto fenómenos, otros meramente pensados por el entendimiento. Así, ya desde el inicio, para Kant (2006):

[...] la palabra fenómeno hará referencia a algo cuya representación inmediata es sensible, pero que en sí mismo tiene que ser algo, es decir, un objeto independiente de la sensibilidad. El concepto de nóumeno se desprende de lo dicho, pero no se trata ni de un concepto positivo ni de un conocimiento determinado de una cosa, sino que significa simplemente el pensamiento de algo en general, pensamiento en el que se hace abstracción de toda forma de la intuición sensible. (p. 269)

Esta diferencia intrínseca entre el objeto para ella y el objeto en sí constituye la finitud de la conciencia. El hecho que las categorías no puedan ser aplicadas a objetos no considerados como fenómenos, sino que sean otra cosa más allá del ser sensible, supone, como se ha planteado, la necesidad de una especie de intuición distinta de la sensible, y se tiene como consecuencia la existencia del nóumeno en un sentido positivo, capaz de ampliar nuestro conocimiento y expandirlo hacia un área en la que no tiene cabida la sensibilidad y, como aquella intuición distinta a la sensible no es posible, entonces lo que entendemos como nóumeno debe entenderse únicamente en un sentido negativo, es decir que "el concepto de nóumeno no es más que un concepto límite destinado a poner coto a las pretensiones de la sensibilidad" (Kant, 2006, p. 272). Así, sigue la firme convicción de Kant de poner límite a todo aquello posibilitado para sobrepasar la capacidad de nuestro entendimiento y hace que incurramos en errores. De hecho, para Kant, al nombrar como nóumenos a las cosas en sí mismas, el entendimiento no es limitado por la sensibilidad, sino que, por el contrario, es aquel el que limita a esta última.

Ahora bien, iqué significa que Kant admita que el concepto de nóumeno, como concepto que pone límites a la sensibilidad, es inevitable? La inevitabilidad de este concepto consiste en que, si Kant tiene que recurrir al "en 
sí" como un límite absoluto, es precisamente para no colocar al fenómeno como único objeto posible del conocimiento. Sin embargo, hay que señalar que, al distinguir el "para nosotros" de la cosa de su ser "en sí" y al afirmar que este "en sí" queda más allá del pensar, Kant establece la finitud del pensar, es decir, admite la incapacidad de la razón para acceder a un contenido específico de la cosa.

Evidentemente Hegel (2007), al igual que Kant, sostiene una concepción del pensamiento como conciencia y, ya desde la "Introducción" a la Fenomenología del espíritu ${ }^{2}$ afirma que "[...] la conciencia es, de una parte, conciencia del objeto y, de otra, conciencia de sí misma; conciencia de lo que es para ella lo verdadero y conciencia de su saber de ello" (p. 58) de modo que, de un lado, la conciencia distingue de sí misma algo con lo que, al mismo tiempo, se relaciona en modo permanente. No obstante, Hegel es muy tajante al afirmar también que, si bien, es cierto que el objeto se presenta para la conciencia como independiente, es decir, se presenta en sí, la conciencia debe esforzarse por mirar detrás del objeto tal como aparece para ver cómo es, para captar realmente su contenido. La conciencia antes de formarse conceptos, se forma representaciones de los objetos y de ahí, tras la experiencia de la conciencia, transita a la construcción de conceptos (Covarrubias Villa, 2017).

La principal consecuencia de una de las maniobras más características de la teoría del conocimiento en Kant y que se ha mencionado varias veces -a saber, la limitación del conocimiento a los fenómenos, sobre el principio de la autosuficiencia del pensar-, consiste en que, Kant, entiende la oposición entre el para ella —el fenómeno como se presenta a los sentidos- y el en sí —el objeto en sí mismo-, como una relación exterior y fija, en el sentido que el único objeto para la conciencia es el fenómeno, mientras que, el en sí, el nóumeno, ese concepto límite de carácter inevitable en la teoría del conocimiento, que sirve para delimitar la capacidad de nuestra sensibilidad, significaría un no-objeto —en oposición al para ella, al fenómeno- que, de hecho, se encuentra más allá de los límites de la propia conciencia. Este más allá designa, precisamente, la inaccesibilidad de la cosa en sí kantiana que se ha señalado como uno de los principales móviles de la crítica hegeliana al kantismo.

${ }^{2}$ Texto que no representa únicamente la introducción a una obra filosófica, sino que, más bien, pretende ser una explicación de en qué debe consistir el filosofar mismo. 
Si la cosa en sí es incognoscible y sólo se puede conocer el fenómeno, es decir, el constructo de pensamiento, las relaciones que las cosas establecen entre ellas son incognoscibles también, ya que sólo es cognoscible el formato fenomenológico que adquieren en la conciencia, es decir, en la relación que establecen con el sujeto. (Covarrubias Villa, 2017, p. 59)

Para Hegel (2007), en cambio, el en sí es un momento de la conciencia que apunta a la trascendencia inmanente del objeto del saber;

El saber es nuestro objeto, es para nosotros; y el en sí de lo que resultara sería más bien su ser para nosotros, lo que afirmaríamos como su esencia no sería su verdad, sino más bien solamente nuestro saber acerca de él. (p. 57)

Lo importante de este punto de vista es que, para Hegel, el hecho de que el saber de un objeto sea solamente para nosotros no tiene como significado que nos encontremos incapaces de tener acceso a esa parte del objeto - de modo que, al igual que en Kant, la finitud de la conciencia sea insuperable-, sino que el en sí del fenómeno no se agota en la conciencia, debido que:

[...] la conciencia misma nos da en ella su propia pauta, razón por la cual la investigación consiste en comparar la conciencia con ella misma, ya que la distinción que se acaba de establecer —es decir, la del objeto en sí y el objeto para la conciencia— recae en ella. (Hegel, 2007, p. 58)

A lo que apunta aquí Hegel es a que, cuando la conciencia mira por detrás para ver cómo es el objeto, esta termina mirándose a ella misma, ya que la separación solamente es un momento interior a ella, con el fin de acercarse al objeto detenidamente.

Para Hegel (2007), la impotencia de la razón, esta finitud de la conciencia, no es una finitud absoluta, ya que, al contener dentro de ella misma - como momento interno a la conciencia- la oposición entre el extremo del fenómeno —el para ella- y el polo del en sí —el nóumeno—, tiene en esa oposición - al ser una oposición inmanente, interna a la conciencia y no una oposición interna al objeto- la completa capacidad de transgredir la escisión 
entre saber y verdad $y$, de este modo, la capacidad de cancelar definitivamente la finitud de la conciencia (pp. 49-50).

Como se ha comentado, la separación kantiana entre nóumeno y fenómeno conlleva la reducción del conocimiento a la experiencia, al saber producto de las impresiones de los sentidos, lo cual representa, para Hegel, la mayor de las incongruencias, debido a que, por un lado, Kant explica que la razón solo es capaz de conocer fenómenos, asumiendo este saber como absoluto y, al mismo tiempo, sostiene que la razón está incapacitada para ir más allá del conocimiento de fenómenos. Es decir que, a fin de cuentas, Kant sostiene la existencia de un absoluto no absoluto (Deleuze, 2008, p. 33).

Hegel, al convertir el en sí en un momento de la conciencia, esta pasa a tener ahora dos objetos: uno es el primer en sí, otro el ser para ella de este en sí. A diferencia del concepto kantiano de experiencia que únicamente significaba el conocimiento, producto de la sensibilidad, para Hegel, esta (la experiencia) es el movimiento de la conciencia en el seno del cual surge, de la diferencia entre el objeto para ella y el objeto en sí (nóumeno y fenómeno), un nuevo en sí que constituye la superación de aquella diferencia y, por tanto, la realización de su verdad; este nuevo en sí es un nuevo objeto que contiene la anulación del primero, es la experiencia hecha sobre el objeto mismo. Con este giro, la conciencia (interior) y el objeto (exterior) poseen la misma naturaleza y que, por lo tanto, el problema de la correspondencia es un falso problema; es decir, que tanto la conciencia como el objeto son formas de una misma realidad objetiva: la dialéctica (Olmedo, 1980, p. 41)

\section{Crítica hegeliana al criticismo kantiano}

El punto clave de la filosofía crítica kantiana consiste en la afirmación de que, antes de emprender el conocimiento de la esencia de las cosas, es necesario investigar si la facultad de conocer es capaz de semejante tarea. Como ya se ha comentado, esta cuestión está directamente relacionada con la posibilidad de existencia de la metafísica como un saber que, de hecho, sirve como base para el conjunto de las ciencias. 
En la "Introducción" a la Fenomenología del espíritu, Hegel ataca toda concepción que retrotrae el conocimiento desde su interés por los objetos a la ocupación consigo, es decir, a lo formal. La crítica de la razón se le presenta a Hegel como un acercamiento a la forma del conocimiento, que se realiza haciendo abstracción del contenido de este, lo cual, en primera instancia, ya puede dar una idea de lo mal visto que resultaba esto para el autor de la Fenomenología, dada la importancia que le otorgaba al contenido del conocimiento. Este viraje del conocimiento sobre sí mismo conlleva, según Hegel (2007), una representación instrumental del conocimiento (p. 21). Evidentemente, Kant en ningún momento realiza explícitamente tal explicación, sino que el profundo estudio del criticismo kantiano llevó a Hegel a concluir que su método, en conjunto con la tesis de la imposibilidad de la metafísica en cuanto conocimiento que Kant pretende justificar como resultado de la crítica de la razón, entrañaba la aceptación de la representación instrumental del conocimiento. ¿Por qué?

Según Hegel, es posible hacer una separación exclusivamente con fines metódicos, de la forma y el contenido del conocimiento. La filosofía crítica, al pretender conocer la facultad del conocimiento antes de entrar al conocimiento objetivo, al conocimiento real de lo que es ente en verdad, tiene por objeto el carácter formal de ese conocimiento, el cual, mediante el análisis, puede ser distinguido y separado de su contenido. Y como el carácter formal del conocimiento es lo que permite aprehender los objetos y captar sus características, la investigación de la forma (la crítica de la razón) se convierte de inmediato en una investigación del medio o del instrumento del conocimiento. La principal crítica hegeliana al respecto consiste en cuestionar el hecho que, en efecto:

[...] si el conocimiento es el instrumento para apoderarse de la esencia absoluta, inmediatamente se advierte que la aplicación de un instrumento a una cosa no deja ésta tal y como ella es para sí, sino que la modela y la altera. (Hegel, 2007, p. 51)

La preocupación de Hegel con respecto al método kantiano radica en que no hay razones suficientes para que no exista desconfianza hacia esta desconfianza kantiana de querer investigar la forma del conocimiento antes de su contenido. Pues, ¿cómo no pensar que este temor a errar sea ya el error mismo? 
A decir verdad, esta crítica está sustentada en tres supuestos que Hegel cree que Kant da por sentados sin examinar idea por idea ni realizar lo que a su juicio es una de las tareas más importantes de la filosofía, el ofrecer y desarrollar el concepto mismo sin dar por hecho que este es bien conocido por todos y provocar algo que ha ocurrido con su misma filosofía, esto es, el surgimiento de malentendidos y la oscuridad conceptual que lo único que provoca es la tergiversación de las ideas originales. Estos tres supuestos son: 1) la representación del conocimiento como un instrumento o un médium, 2) la diferenciación entre nosotros mismos y ese conocimiento, y 3) la escisión entre el absoluto y el conocimiento (Miranda Mora, 2017, pp. 5-6).

Así, el proyecto que nos plantea Hegel con estos supuestos tiene dos objetivos: 1) demostrar la tesis de que solo lo absoluto es verdadero o solamente lo verdadero es lo absoluto (por medio de la exposición de la ciencia hacia el saber), pues solo a partir de la confirmación de esta tesis el miedo al error como motivación del proyecto moderno se mostrará como infundado; y 2) En el análisis de los presupuestos, arriba expuestos, Hegel se encargará de mostrar por qué el conocimiento no necesita ni de un método para probarlo, ni de un principio que funcione como fundamento para asegurar su verdad (Miranda Mora, 2017, p. 6).

Por tanto, antes de explicar las consecuencias de cada uno de estos supuestos hay que dejar en claro que la crítica hegeliana del criticismo kantiano implica una ruptura con respecto a la teoría del conocimiento imperante en la época, ya que Hegel reclama a Kant el haber ignorado en su crítica ciertas opiniones asumidas sin previo examen.

\subsection{El conocimiento como un instrumento o un médium}

Al exponer, a grandes rasgos, el argumento hegeliano contra la pretensión kantiana de examinar los límites de la razón antes de entrar al conocimiento objetivo, al conocimiento de lo que es ente en verdad, la consecuencia de esta metodología implica para Hegel un viraje del conocimiento sobre sí mismo que trae consigo ni más ni menos que la representación del conocimiento como un instrumento. 
El argumento de Hegel consiste en distinguir el hecho de que la crítica de la razón —es decir el estudio del instrumento con el que se lleva a cabo el conocimiento de los objetos- es desde un inicio un conocimiento, y que, por lo tanto, conlleva el uso de este instrumento. Evidentemente, el hecho de que sea prácticamente imposible investigar la naturaleza y alcances de la razón sin emplearla no evita que de hecho haya en nuestro mundo práctico algunos instrumentos que puedan examinarse antes de realizar el trabajo llevado a cabo por ellos, sin embargo, Hegel es muy directo cuando resalta la obviedad de que la actividad que se lleva a cabo por medio de la facultad de conocer es precisamente el conocimiento de objetos, de modo que

siquiera intentar conocer la facultad de conocer antes de conocer el mundo objetivo es imposible, lo que resulta en que dicha representación instrumental del conocimiento por parte de Kant engendra un problema sumamente serio: la imposibilidad de la crítica misma. (Hyppolite, 1974, pp. 192)

A decir verdad, este es uno de los puntos clave en el desarrollo de la crítica hegeliana del criticismo kantiano. Hegel se encuentra aquí ante una disyuntiva que definirá su proyecto filosófico, debido a que esta toma de postura afecta no solo a su comprensión de la epistemología kantiana, sino, además, servirá como punto de quiebre en la construcción de una filosofía que exponga el saber tal como se manifiesta. Hegel tiene dos opciones: "negar la crítica como una tarea necesaria y primaria al conocimiento de lo objetivo y por tanto omitirla, o retomarla superando la escisión entre crítica y conocimiento objetivo" (Hyppolite, 1974, p. 196).

Al superar la escisión entre crítica y conocimiento objetivo, Hegel se coloca en camino a lograr uno de los objetivos planteados desde el inicio: lograr que la filosofía deje de ser solo amor al conocimiento para convertirse en saber real, y por esta vía, superar la escisión entre objeto y pensamiento. Se trata de sostener el carácter absoluto del conocimiento filosófico pues, según Hegel (2007):

la ciencia no puede rechazar un saber no verdadero sin más que considerarlo como un punto de vista vulgar de las cosas y asegurando que ella es un conocimiento completamente distinto y que aquel saber no es para ella 
absolutamente nada, ni puede tampoco remitirse al barrunto de un saber mejor que él mismo. (p. 53)

Ya que esto conllevaría la existencia de un conocimiento de lo verdadero que deje subsistir fuera de él otro saber finito y cancelaría el conocimiento absoluto. El yo es universal; en cuanto voluntad, me encuentro en mi libertad, en mi universalidad misma, en la universalidad de mi autodeterminación; y si mi voluntad es racional, sus determinaciones son, en general, algo universal, unas determinaciones según el concepto puro (Hegel, 1998, p. 154).

Para Hegel, la totalidad de las formas de la conciencia se alcanza a través de la necesidad del proceso y la cohesión mismas. En este sentido, la no renuncia a la crítica de la razón implica para Hegel la mediación entre el saber verdadero y el saber finito. Hegel percibía a la metafísica como necesitada de legitimación, por lo que si el conocimiento de lo absoluto — partiendo de la premisa de que solamente lo absoluto es verdadero y solamente lo verdadero es absoluto - está mediado por el conocimiento finito y lo tiene como presuposición, entonces el conocimiento de lo absoluto ha de basarse en una crítica del conocimiento. Ahora bien, ¿en qué consiste dicha mediación entre conocimiento finito y conocimiento absoluto y por qué esta presupone la crítica?

Como se ha visto, la ciencia no puede rechazar un saber verdadero sin más que considerarlo como un punto de vista parcial o vulgar de las cosas, sin embargo en lo que hay que poner especial atención es en el hecho de que, a la inversa, tampoco se puede aceptar cualquier punto de vista (cualquier conocimiento finito) como presuposición del conocimiento absoluto, sino que la mediación solo puede ser válida si aquel conocimiento finito con el que se empieza a conocer no es aceptado azarosamente sino que representa una verdad primera. Se trata aquí de concebir el conocimiento finito como conocimiento absoluto en su forma no mediada o desarrollada. "Este movimiento dialéctico que la conciencia lleva a cabo en sí misma, tanto en su saber, como en su objeto, en cuanto brota ante ella el objeto verdadero, es propiamente lo que se llamará experiencia" (Hegel, 2007, p. 58). Al resultar que la crítica de la razón y el conocimiento absoluto se encuentran unidas de forma 
interna, el saber finito deviene mediación del conocimiento absoluto, en la medida en que representa una verdad primera fundamentada en lo absoluto.

En resumen, lo que en primera instancia aparece como un impedimento para Hegel —la representación instrumental del conocimiento- se convierte en la clave para entender su concepto de mediación, en el que, debido a que esta está fundada en la verdad — en una verdad no mediada o desarrollada - se cancela a sí misma, de modo que el saber finito se autosupera y deviene ciencia. Prescindir del contenido objetivo del conocimiento tiene, para Hegel, un vacío de conocimiento y no, como pretende Kant, un conocimiento de la forma del mismo. Por esto, lo que Kant entendía como dos tipos de conocimiento, que si bien estaban relacionados exteriormente -forma y contenido del conocimiento-, Hegel los entiende como dos momentos que surgen y se relacionan al interior de la propia experiencia. Así, según Reynner (2013) "lo real no sólo es la forma como concebimos el mundo, pues gracias a él pensamos nuestro mundo y nos pensamos en el mundo, sino la lente a través de la cual vemos (concebimos) nuestro ser y nuestro mundo" (p. 150).

\subsection{Diferencia entre nosotros y el conocimiento}

Al lograr convertir la crítica de la razón en un momento interior a la experiencia, de modo que se realiza una identidad entre el sujeto de la crítica y el sujeto de la experiencia, Hegel se enfrenta al externalismo de fundamentación de la moderna teoría del conocimiento. Hegel compartía la concepción de la metafísica racionalista que elevaba la certeza al grado de verdad, de modo que la conciencia tenía la capacidad de ver los objetos como eran realmente; sin embargo, con la especificidad del escepticismo kantiano, que fuertemente Hegel señala como un temor a la verdad, "la certeza deja de tener el grado de verdad del que gozaba y se presenta ahora únicamente como el primer paso en el conocimiento" (Hyppolite, 1974, p. 201).

Hasta ahora se ha hecho énfasis en la importancia que tiene para la filosofía hegeliana la confrontación con el criticismo kantiano. Hegel considera que la filosofía crítica entiende la relación entre nosotros, la cosa y los conceptos que de ella tenemos como una relación exterior y, por lo tanto, insuperable, en la que los conceptos en vez de unirnos a las cosas, nos separan de ellas y crean la 
apariencia de insuperabilidad de esta separación que, como también ya hemos dicho, deviene en la aceptación de la realidad dada y, por lo tanto, en la imposibilidad de transformación de la realidad. La representación instrumental del conocimiento en la que forma y contenido quedan irremediablemente separados y se reduce, así, el ser de la cosa a su ser para nosotros, y se relega a un indeterminado más allá su ser en sí, no solo implica para Hegel la separación entre nuestros pensamientos y el conocimiento, sino que, en última instancia, implica la separación entre subjetividad y objetividad, que marca el hilo conductor de la concepción moderna de la razón que Hegel critica.

La distinción que hace Hegel (2007) en el prólogo de la Fenomenología del Espíritu, que representa la génesis de este trabajo, en donde afirma que "todo depende de que lo verdadero no se aprehenda y se exprese como sustancia, sino también y en la misma medida como sujeto" (p. 15), es una crítica feroz hacia la concepción moderna de razón de la cual Kant es su máximo representante, sin embargo, el punto clave para la comprensión de esta frase que condensa el problema filosófico más importante en la modernidad, es el destacar que esta afirmación incluye concebir la verdad no solo como sujeto, sino también y en la misma medida como sustancia, lo que significa trascender la escisión abierta por Kant entre nosotros y las cosas.

Según Hegel:

[...] el saber es nuestro objeto, es para nosotros; y el en sí de lo que resultara sería más bien su ser para nosotros; lo que afirmaríamos como su esencia no sería su verdad, sino más bien solamente nuestro saber acerca de él. (Hegel, 2007, p. 57)

Sin embargo, el ataque de Hegel está dirigido en contra de la reificación de subjetividad y objetividad como dos principios relacionados externamente. La concepción hegeliana de estos dos principios apunta a dejar de representarse el pensar como algo subjetivo y a la cosa como algo externo al pensamiento, sino que tanto pensamiento, como objetividad, deben entenderse siendo cada uno en relación entera con el otro. La noción hegeliana de concepto entraña la inseparabilidad entre la esencialidad de nuestro pensar y la subjetividad de la cosa pensada; es decir, apunta hacia la sustancialización del pensamiento —su exteriorización y, por lo tanto, la transgresión del orden de cosas dado-, así 
como la subjetivación de la objetividad. Es en este sentido en que Hegel (2007) afirma que este proceso se puede definir como:

el camino de la conciencia natural que pugna por llegar al verdadero saber o como el camino del alma que recorre la serie de sus configuraciones como otras tantas estaciones de tránsito que su naturaleza le traza, depurándose así hasta elevarse al espíritu y llegando, a través de la experiencia completa de sí misma al conocimiento de lo que en sí misma es (p. 54)

\section{Separación entre lo absoluto y el conocimiento}

El presupuesto kantiano que concierne a la separación entre lo absoluto y el conocimiento debe analizarse a la luz de una afirmación que Hegel hace en la "Introducción" a la Fenomenología del espíritu inmediatamente después de mencionar lo enunciado por parte de Kant. "Solamente lo absoluto es verdadero o solamente lo verdadero es absoluto" (Hegel, 2007, p. 52). Además del evidente ataque hacia Kant, por parte de Hegel, hay que analizar esta afirmación fundamental en la filosofía hegeliana desde la relación que, en ese momento, llevaba Hegel con Schelling y la visión que tenía el primero sobre el trabajo del segundo. Inmediatamente después de ofrecer su toma de postura con respecto al concepto de "lo absoluto", Hegel ataca toda filosofía que coloque al conocimiento como un instrumento para posesionarnos de lo absoluto o como un médium para incluir la verdad y rechaza la validez del uso de ciertos conceptos por parte de los filósofos (Schelling y Kant) como lo absoluto, el conocimiento, lo objetivo y lo subjetivo y algunos otros. Hegel define el uso de estos conceptos sin su previa exposición, como una manifestación vacía del saber.

Cuando Hegel atacaba -indirectamente, aunque con bastante obviedad - al gran maestro de la filosofía alemana, Kant, y a uno de sus más brillantes sucesores, Schelling, evidentemente tenía bien definido el alcance de dicha crítica. Es verdad que algunos detractores de Hegel bien podrían afirmar que este repitió precisamente lo que estaba atacando y que el uso de conceptos como "absoluto" o "espíritu" son utilizados deliberadamente en virtud del afán de explicar alguna idea, sin embargo, para bien o para mal, es indudable el hecho que, una vez aceptando los supuestos del sistema hegeliano, es imposible salir de él y es precisamente esto lo que Hegel reprochaba a Kant y, al menos en 
cuanto corresponde al absoluto y, a Schelling, la inconsecuencia de algunos de sus más importantes argumentos, mismos que no encontramos en Hegel (Hyppolite, 1974, pp. 366-368).

Si bien la crítica a los presupuestos kantianos se encuentra en la "Introducción" a la Fenomenología del espíritu, es oportuno trasladarse, por un momento, al prólogo de la obra — que fue escrito ya terminada la misma y es considerado como la ruptura definitiva entre Hegel y su amigo Schelling- con el fin de dejar en claro, al menos, dos aspectos de la crítica hegeliana hacia estos dos filósofos. En el mismo prólogo, Hegel (2007) afirma que:

[...] hacer pasar su absoluto por la noche en la que, como suele decirse, todos los gatos son pardos, es la ingenuidad del vacío del conocimiento. El formalismo que la filosofía de los tiempos modernos denuncia y vitupera y que constantemente se engendra de nuevo en ella no desaparecerá de la ciencia, aunque se lo conozca y se lo sienta como insuficiente, hasta que el conocimiento de la realidad absoluta llegue a ser totalmente claro en cuanto a su naturaleza. (p. 15)

En el primer enunciado, del párrafo anterior, se puede afirmar, casi con total certeza, que está dirigido a Schelling. El ataque de Hegel consiste en dudar de toda aquella filosofía que pretenda hablar del conocimiento absoluto y se desentienda, así, de todas las particularidades propias del conocimiento humano, queriendo abarcarlo todo sin abarcar absolutamente nada. Además, es bien conocido que, luego de su periodo de reconciliación en Jena en donde trabajaron juntos e incluso colaboraron en la edición de una revista de filosofía, el prólogo a la Fenomenología del espíritu, representó la separación definitiva entre Schelling y Hegel, sin embargo, aunque era importante señalar la referencia a Schelling al menos en el tema de lo absoluto, lo fundamental es el ataque a la filosofía kantiana y sus presupuestos.

La segunda parte de la cita refiere completamente a Kant. La frase el "formalismo de los tiempos modernos" es algo que se debe agradecer $-\mathrm{O}$, en este caso, reprochar - al autor de la Crítica de la Razón pura. El presupuesto kantiano que coloca al conocimiento de un lado y al absoluto del otro, da por hecho que puede existir un conocimiento que no tenga por objeto lo absoluto, es decir, da por hecha la existencia de una verdad no absoluta y, por otro lado, supone la idea del absoluto como algo trascendente al conocimiento, lo que 
significaría la aceptación de un absoluto no verdadero (Rosas, 1996, p. 72). Este resultado está directamente relacionado con un aspecto de la filosofía kantiana que ya examinamos, a saber: el dualismo que se encuentra en ella (la filosofía) al permanecer presa entre el principio empirista en el que el criterio de cognoscibilidad es la intuición y el principio racionalista que supone la autosuficiencia del pensar, dualismo cuya consecuencia hemos definido como la separación de la cosa entre su ser sensible (fenómeno) y su ser en sí (el nóumeno).

Al contrario de Kant, para Hegel, "no existe separación alguna entre el conocimiento y lo absoluto, debido a que su objetivo era lograr que la filosofía dejase de ser un amor al saber para colocarse como el saber mismo" (Hyppolite, 1974, p. 370). En esta línea, la existencia de un conocimiento fuera de lo absoluto es imposible. Se trata ya de la búsqueda de un conocimiento que, aunque no sea él mismo absoluto, forme parte de este, no en el sentido de una relación exterior entre conocimientos particulares y el absoluto, sino de un conocimiento que, si bien en su forma no desarrollada, pertenece al ámbito del absoluto y lo presupone. Se trata, en este sentido, para Hegel (2007) que:

la meta es la penetración del espíritu en lo que es el saber. La impaciencia se afana en lo que es imposible: en llegar al fin sin los medios. De una parte, no hay más remedio que resignarse a la largura de este camino, en el que cada momento es necesario, y de otra parte, hay que detenerse en cada momento, ya que cada uno de ellos constituye de por sí una figura total individual y sólo es considerada de un modo absoluto en cuanto que su determinabilidad, se considera como un todo o algo concreto o cuando se considera el todo en lo que esta determinación tiene de peculiar. (p. 22)

\section{Conclusión}

Como se puede observar en toda su obra, Hegel insiste en la largura del camino de la inmediatez del conocimiento al conocimiento absoluto. La crítica hegeliana del criticismo o teoría del conocimiento kantiano que se acaba de esbozar significa el punto de partida en el desarrollo de las ideas más importantes dentro de la obra del filósofo alemán, de modo que esta confrontación con el pensamiento kantiano es fundamental para su comprensión. Por tanto, después de este interesante enfrentamiento entre la controversia epistemológica Hegel- 
Kant se puede sustentar que para Hegel existe una correspondencia absoluta entre lo real y lo racional como forma de conocimiento; en tanto que para Kant lo real es incognoscible por lo que solo se cuenta con lo que de él se piensa como forma de conocimiento (Covarrubias Villa, 2012, p. 55).

Aunque Hegel no menciona directamente a Kant en la Fenomenología del Espíritu, es importante estudiar algunos de sus apartados más importantes desde esta crítica a la concepción kantiana del conocimiento. La originalidad de Hegel no consiste en construir su filosofía a partir de la nada, sino, más bien, de retomar el avance de la filosofía hasta su tiempo y ampliarla hasta convertirla en un pensamiento que apunte a condensar dentro de sí todas las posturas filosóficas más importantes. Y, así, partiendo del estudio crítico hegeliano y considerando la teoría del conocimiento de Kant, el acercamiento a los temas fundamentales que componen la obra clave de la filosofía de Hegel, resultará menos complicado.

En suma, el punto clave de la crítica hegeliana del criticismo kantiano es, sin duda, la afirmación que indica que "todo depende de que lo verdadero no se aprehenda y se exprese como sustancia, sino también y en la misma medida como sujeto" (Hegel, 2007, p. 15), debido que expresa, por completo, la importante distinción entre un filósofo y otro. Con esta afirmación, Hegel deja en claro su concepción sobre los alcances de la razón que, como se ha mencionado, no se encuentra imposibilitada para acceder hacia ese "más allá" de la conciencia, ese nóumeno representado por Kant que era considerado como inaccesible y ponía límites al conocimiento. Se trata más bien, según Hegel, de adecuar la realidad conforme con el pensamiento, de construir una identidad entre lo sustancial, la objetividad, la historia y el sujeto, el pensamiento, el hombre de carne y hueso. Y, por tanto, entender desde su completitud epistemológica la afirmación hegeliana que nos dice que todo lo real es racional y que todo lo racional es real.

\section{Referencias}

Althusser, L. (2000). La filosofía como arma de la revolución. Siglo XXI Editores. 
Covarrubias Villa, F. (2012). Los dos senderos de la episteme: conocimiento científico en la tradición de Platón y Aristóteles. Revista Paradigmas, 4(1), 41-66.

Covarrubias Villa, F. (2017). La naturaleza de lo real. Carteles Editores.

Deleuze, G. (2008). Filosofía crítica de Kant. Cátedra.

D'Hondt, J. (2002). Hegel. Tusquets Editores.

Fink, E. (2014). Hegel: Interpretaciones fenomenológicas de la Fenomenología del Espíritu. Herder.

Hegel, G. W. F. (1978). Escritos de juventud (Z. Szankay \& J. M. Ripalda, trads.). Fondo de Cultura Económica.

Hegel, G. W. F. (1998). El concepto de religión (A. Ginzo, trad.). Fondo de Cultura Económica.

Hegel, G. W. F. (2007). Fenomenología del Espíritu (W. Roces, trad.). Fondo de Cultura Económica.

Hyppolite, J. (1974). Génesis y estructura de la "Fenomenología del espíritu" de Hegel (F. F. Buey, trad.). Península.

Kant, I. (2006). Crítica de la razón pura (P. Ribas, trad.). Taurus.

Labrador Montero, D. (2018). Sobre la división de la razón en Kant: la ruptura con el sistema de racionalidad absoluta. Revista de Humanidades de Valparaíso, 6(11), 39-74. https://doi.org/10.22370/rhv.2018.11.854

Manzano Vargas, J. (2013). Apuntes de historia de la filosofía: Emmanuel Kant. ITESO.

Marcuse, H. (1979). Razón y Revolución. Alianza Editorial.

Miranda Mora, A. M. (2017). Hegel y el escepticismo. Revista Reflexiones Marginales, 14(1), 1-9.

Nietzsche, F. (1993). Aurora: reflexiones sobre la moral como prejuicio (E. López Castellón, trad.). M. E. Editores.

Nietzsche, F. (2007). Más allá del bien y del mal (A. Sánchez Pacual, trad.). Alianza Editorial.

Olmedo, R. (1980). El antimétodo: introducción a la filosofía marxista. Joaquín Mortiz.

Reynner, F. (2013). La ansiada apariencia de lo real. Sobre la no anulable pretensión de objetividad de la experiencia epistemológica de McDowell. Revista Argos, 30(58), 145-159.

Rosas, A. (1996). Fenómeno, nóumeno y mente en Kant. Arete: Revista de filosofía, 8(1), 65-80. 